\title{
Empirical Analysis of Factors Contributing to Smartphone Addiction
}

\author{
Megan Emfosi Meena1 ${ }^{*}$, Shao Kang1, Benedictor Alexander Nguchu², Nalugoti Milly', \\ Jesse Jackson Makwetta ${ }^{1}$, Akwi Helene Fomude ${ }^{1}$ \\ ${ }^{1}$ School of Economics and Management, Anhui University of Science and Technology, Huainan, China \\ ${ }^{2}$ Hefei National Laboratory for Physical Sciences at Microscale, University of Science and Technology of China, Hefei, China \\ Email: *megan.meena17@gmail.com, seeke@qq.com, benedictoralexander@yahoo.com, millykay7@gmail.com, \\ jmakwetta@yahoo.com, lenafomude@gmail.com
}

How to cite this paper: Meena, M. E., Kang, S., Nguchu, B. A., Milly, N., Makwetta, J. J., \& Fomude, A. H. (2021). Empirical Analysis of Factors Contributing to Smartphone Addiction. Open Journal of Business and Management, 9, 213-232. https://doi.org/10.4236/ojbm.2021.91012

Received: November 26, 2020

Accepted: January 9, 2021

Published: January 12, 2021

Copyright $\odot 2021$ by author(s) and Scientific Research Publishing Inc. This work is licensed under the Creative Commons Attribution International License (CC BY 4.0).

http://creativecommons.org/licenses/by/4.0/

\begin{abstract}
Purpose: The purpose of this paper is to analyze the effects of loneliness, shyness, social anxiety, and external locus of control on the smartphone addiction among undergraduate, graduate, and postgraduate students in China. Methodology: Our research used questionnaires as a method of response generation. 240 returned questionnaires were useable from which results were derived. We used Pearson's Correlation Analysis to analyze the relationships between the variables and their significance. The reliability of the study was assessed through Cronbach's Alpha. Result and Findings: The analysis of the study revealed that the variables were significant and positively correlated with each other. Loneliness had a strong correlation to smartphone addiction, shyness and social anxiety were moderately correlated, whereas, external locus of control was weakly correlated to smartphone addiction. Research Implications: This study can be used by universities and educational ministries in China in order to understand the behaviors and addictions of students and can devise strategies on how to successfully tackle this situation in students. Limitations: The respondents' pool of this study is constricted and only involves students in China. The analysis is purely quantitative and this study was conducted on a cross-sectional basis. Future Research: Further research can be conducted by diversifying the pool of respondents, conducting a longitudinal study, and employing qualitative methods to analyze the research.
\end{abstract}

\section{Keywords}

Loneliness, Shyness, Social Anxiety, External Locus of Control, Smartphone Addiction 


\section{Introduction}

There's no doubt that smartphones are extremely helpful, reliable and everything a person needs. While previously there used to be different devices for different purposes such as a calculator for math, stereos for music, personal computers for work and gaming, radio for listening to the news, television for watching shows, etc. Nowadays, all of those things have been compiled in a single, compact device that we all know as smartphones. It contains all our contacts, our work assignments, our projects, our homework, music, pictures, GPS, etc. Everything that we need is a click away. Not only that but it has a major use for entertainment as well through the social networking sites. No wonder we have it with us all the time. Moreover, it's now easier than ever to connect with people and stay in touch with them through applications like WeChat with their features of instant messaging, voice calls and video calls free of cost.

Mobile phones are now a vital part of one's everyday life since everything is stored on this small machine. It is difficult to let even an hour go by without checking your phone. It has become very difficult for individuals to separate from their smart device (Lepp et al., 2015). Smartphones are changing the way people live their lives. They are changing the integral parts of our lives such as our bond with our families, relationships, social behavior, habits, norms, values, etc. the addiction of mobile phone usage has been linked to a number of reasons including, but not limited to, stress, withdrawal, anxiety, family disruptions, deterioration of personal health and academic performance (Thomée, Härenstam, \& Hagberg, 2011).

In this research, we will be exploring the relationship of loneliness, shyness, social anxiety and external locus of control, and how these feelings of an individual contribute towards being addicted to smartphones. The level of smartphone addiction can be identified by its leading factors that include daily life disturbances, withdrawal, cyber-oriented relationships, overuse, tolerance, and positive anticipation. While it is fairly plausible to believe that smartphone has a number of advantages and people may be using it for its benefits in academia, knowledge, innovation, etc. but an addiction of any substance is never positive. Therefore, we will be studying the factors that lead to mobile phone addiction among the undergraduate, graduate and post-graduate level students of universities in China.

This study is further divided into different sections, following the structural flow of literature review, where we will be defining and introducing the variables, followed by research methodology where we introduce our model and develop hypothesis. This section will also contain the information regarding data collection, sampling and measures of our variables. After that, we will discuss the statistical analysis and the analysis of the variables in relation with each other, and finally conclusion of our research.

\section{Literature Review}

\subsection{Loneliness}

In many theories over the years, there is one that has always remained constant, 
i.e. humans are social animals. This means that people need the daily dose of social interaction, social relationships, communication etc. to survive, function properly, and maintain their quality of life. In these terms, it can be deduced that their life will take a hit if these conditions deteriorate (Kara et al., 2020). One reason for the deterioration of social involvement is loneliness.

Peplau, Russell, \& Heim (1979) have described loneliness as perceived deterioration in an individual's relationships with people in terms of quantity and quality. A person is faced with such deficits in their relationships when the number of their company or their value does not come up to expectation and satisfaction (Peplau et al., 1979). Different studies, conducted by Jones (1982) and Spitzberg \& Canary (1985) have also concluded that there was a positive correlation among an individual's loneliness and lack of social interaction when conversing with others. Sloan \& Solano (1984) and Solano, Batten, \& Parish (1982) have defined loneliness as one's inability to be talkative, show a higher participation in social environments, and to talk about themselves in to an appropriate degree. Spitzberg \& Canary (1985) have said that loneliness leads one to remain incompetent in personal relations, hence remaining in their own company and showing less involvement in social events. It is described by Asher \& Paquette (2003) and Yildiz \& Duy (2014) as being mentally aware of one's own deficit of social circle and feeling an emotional strain of despair, longing and awareness. Therefore, we can now divide it into two components, i.e. social and emotional (Weiss, 1973).

\subsubsection{Social Loneliness}

An individual feels socially lonely when he perceives himself at a distance from his society and feels like an outsider within a group of people who have similar interests and partake in similar activities (Duy, 2003).

\subsubsection{Emotional Loneliness}

Emineoğlu (2018) describes it as having a deficit of close personal relationships with another and feeling anxious and empty inside.

Therefore, different researchers have described loneliness in a number of different ways according to their studies. One thing that they all agree on is the fact that it is an unpleasant condition for a person rather than a choice of seclusion and isolation; and that it results in negative feelings of the one suffering from it.

\subsection{Shyness}

Different researchers have defined shyness in various ways. Asendorpf (1991), Coplan \& Armer (2007) and Rubin et al. (2009) have described shyness as an individual's reaction of uneasiness and caution when put in a social situation. It is believed that people may have the desire to interact socially with people but their dread, insecurity and limited self-confidence stop them from doing so (Chen, 2018). Shyness also intersects different concepts regarding the emotional stimulation in social settings such as anxious solitude (Gazelle \& Ladd, 2003; Shell, 
Gazelle, \& Faldowski, 2014), anxious withdrawal (Oh et al., 2008), and social withdrawal (Rubin et al., 2009). It is also described as feeling uncomfortable in social gathering, while also being frustrated with the internal force obstructing an individual from participating in such events (Henderson \& Zimbardo, 2001). Cheek \& Buss (1981) define it as an individual's behavior of interacting with strangers or casual associates, including tension, anxiety, feeling uneasy and uncomfortable, and both gaze aversion and inhibition of normally expected social behavior. Therefore, Pilkonis (1977) believes that a feeling of anxiousness when being observed by others in a social setting is the determinant of shyness.

Shyness can be the cause of a number of different problems. It poses a hindrance in satisfying communication which can lead to improper and frustrating communication, anxiety disorder (Van, Mancini, \& Oakman, 1998), loneliness (Tan, Ai, Wen, Wu, \& Wang, 2016; Cheek \& Buss, 1981; Jackson, Frinch, \& Nagasaka, 2002; Zhao, Kong, \& Wang, 2013), depression (Alfano, Joiner, \& Perry, 1994; Romney \& Bynner, 1997), and drug and alcohol addiction (Brook \& Newcomb, 1995; Dobkin et al., 1995; Ensminger et al., 2002; Hawkins, Catalano, \& Miller, 1992; Kellam, Simon, \& Ensminger, 1983).

\subsection{Social Anxiety}

Anxiety is described by Schlenker \& Leary (1982) as a mental and emotional response of an individual when faced with a situation in which he believes that there is no way to avoid the approaching negative outcome. There are a number of different forms of anxiety, but when talking about social anxiety, it is referred to as the fear of being judged by others on personal traits in existent or fictional situations (Schlenker \& Leary, 1982). Leary (1983) is of the opinion that individuals suffering from social society tend to avoid social gatherings and go into isolation. It is described as when an individual is overcome by the feeling of dread and uneasiness when in an attempt to initiate conversation with someone, or trying to intermingle, and feeling as if there are people to evaluate him (Jatmiko, 2016).

When talking about anxiety and its relationship with excessive use of smartphones, there are a lot of studies present that corroborate this relationship. Different studies conducted by a number of researchers have linked the use of mobile phones and internet addiction with certain different variables such as anxiety, strained family relations, depression and stress (Huang et al., 2009; Charlton \& Danforth, 2010; Hawi, 2012; Müller et al., 2014; Kabasakal, 2015). Yen et al. (2007) are of the opinion that people who suffer from social anxiety and isolation find their solace in online interactions. In a research conducted by Elhai et al. (2017), it was found that there were a number of common variables that have been studied in relation to their effect upon mobile addiction and usage and anxiety was one of those variables. Anxiety was found to have a significant effect on smartphone usage because it was found to be a way for people to curb their anxiety in social situations (Demirci et al., 2015; Lee, 2014; Koh \& Kim, 2017). 


\subsection{External Locus of Control}

The concept of locus of control was originally presented in 1954 by Julian Rotter. He postulated it as an internal or external orientation. The internal locus of control refers to an individual's perception that the outcome of his actions and life is all his own doing and he is in control of it all; whereas, external locus of control refers to an individual's perception of outcomes being influenced by others or by fate (Rotter, 1966; Keenan \& McBain, 1979). People with greater internal orientation try to take charge of their own environment, whereas, those with external orientation feel stranded and helpless because they think that nothing is in their control (Keenan \& McBain, 1979; Hsiao et al., 2016). Therefore, locus of control can be divided into three parts:

1) Internal Control (Internal Locus of Control): This includes one's own actions and being internally oriented.

2) Chance (External Locus of Control): It is a perception that things happen because of accidental happenings, bad happenings, or luck.

3) Powerful Others (External Locus of Control): It is a perception that things occur due to pressure groups, powerful others or powerful people.

Locus of control has been used in a number of studies regarding the coping mechanisms related to certain coping styles (Lazarus \& Folkman, 1984; Newton \& Keenan, 1990; Van den Brande et al., 2016). When talking about external locus of specifically it has been correlated with poor coping mechanisms, higher level of stress and poor health management (Evers et al., 2000; Gianakos, 2002; Gore et al., 2016). People rating high on external locus of control would then try to control anything they can in their lives to achieve some sense of control. This eventually leads to higher levels of smartphone addiction. Therefore, we will be focusing on only the external locus of control (i.e. chance and powerful others) in our research.

\section{Conceptual Framework and Hypothesis}

\subsection{Conceptual Framework}

In order to analyze the effects of loneliness, shyness, social anxiety, and external locus of control on smartphone addiction, we propose the following hypothetical model presented in Figure 1.

\subsubsection{Loneliness and Smartphone Addiction}

With rapid technological innovations taking place every day, and new social apps being made, it has removed man from the society. Nowadays, people can stay in touch with each other without having to interact personally. This can result in an individual feeling lonely and relying on smartphones to get rid of that loneliness. Too much reliance can lead to an addiction of this device. Sar. (2013) is of the opinion that relying on the use of smartphones for emotional support and getting rid of loneliness can eventually lead to addiction. Engelberg \& Sjoberg (2004) stated in their study that lonely people crave the use of internet. 


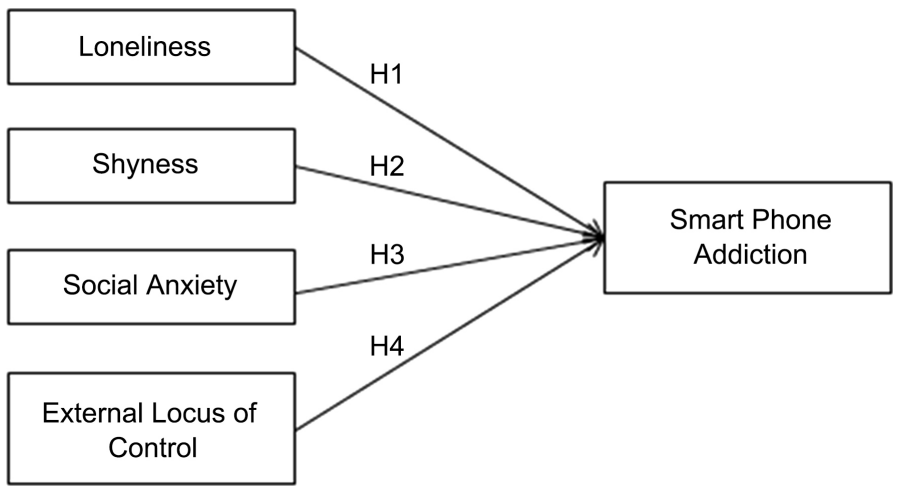

Figure 1. Conceptual framework.

Since smartphones provide an easy portal to the internet world, therefore, they get addicted to it. Even if we talk about the basic purpose of a simple mobile phone, it helps people communicate with each other at a distance; hence people might use it for this simple reason as well to eliminate the feelings of loneliness (Townsend, 2000). Casey (2012) provided a list of symptoms that can help people identify if they are addicted to smartphones. These symptoms include decreased productivity, feeling anxious when they don't have their phone, extreme desire for the object, paying no heed to its harmful consequences, and continuously thinking about your phone and its activities.

Therefore, people with low self-esteem, lack of confidence, isolation, and psychological disorders are more likely to be addicted to the use of smartphones. Park (2005) stated in his study that college students who are experiencing loneliness are at a greater risk to be addicted to smartphones. Since people suffering from loneliness lack confidence, they prefer interacting with others through phone calls, text messages or any other means of communication, except face-to-face. Hence, this leads us to our first hypothesis.

\section{$\mathrm{H} 1$ : Loneliness is positively correlated with smartphone addiction.}

\subsubsection{Shyness and Smartphone Addiction}

In a number of researches, shyness has been positively correlated with different variables such as problematic internet use (Odacı \& Çelik, 2013; Tian et al., 2017), and the addiction to mobile phones (Bian \& Leung, 2015; Han et al., 2017). The use of smartphones and internet provides a safe, secure and distant environment for shy individuals (McKenna \& Bargh, 2000). It exhibits the options of invisibility and anonymity when interacting online or through social networking sites which serves as an attractive means of communication for bashful individuals and they may express themselves more frankly (Saunders \& Chester, 2008; Suler, 2004). Therefore, because of this ease of communication while still being in their personal space provides a better alternative to personal communication (Laghi et al., 2013). Bashful individuals prefer online interactions rather than face-to-face communication to satisfy their anxiety and discomfort in situations involving personal interactions (Han et al., 2016). The 
more comfortable they get with using smartphones as their medium of communication, the more they will stay away from social interactions and the more they will get addicted to using smartphones for all kinds of interactions (Saunders \& Chester, 2008). Because of the vast range of accessibility that is provided by the internet on smartphones, people who suffer from shyness choose this over any interaction whether they are waiting for someone, travelling on a bus, waiting in a queue, etc. they tend to pass their time while using their smartphones (Chotpitayasunondh \& Douglas, 2016). Slowly but surely, this addiction would consume them; and they will leave the real world far behind them. Other scholars are also of the opinion that there is a strong correlation between shyness and smartphone addiction (Bian \& Leung, 2015; Han et al., 2017). Hence, this leads us to our second hypothesis.

$\mathrm{H} 2$ : Shyness is positively correlated with smartphone addiction.

\subsubsection{Social Anxiety and Smartphone Addiction}

Smartphone addiction serves as a means to avoid anxiety (Koh \& Kim, 2017). There are many instances when individuals tend to use their smartphones when in a public area waiting for someone. This is not particularly because there is anything interesting on the smartphone; the individual might even be scrolling through the apps, it is a means to relieve their social anxiety. Hormes et al. (2014) found in his research that the use of social networking sites has the power to make one forget about their emotional problems, which includes anxiety. This hypothesis was supported by Grieve et al. (2013) when they found that the use of Facebook resulted in reducing anxiety among individuals. The fact that immersing in smartphones and communicating through it is such an attractive means for anxious people is because it helps to avoid uncomfortable social situations (Pugh, 2017; Yen et al., 2007). Valkenburg, Peter, \& Schouten (2006) are of the opinion that this use of smartphone for accessing social networking sites is also useful because it gives the people with anxiety enough time to get prepared for any kind of interaction beforehand. Moreover, people suffering from anxiety prefer to communicate through texts rather than over the phone, which gives them a sense of comfort and the power to control the communication to some extent (Pugh, 2017). In the light of this literature, it suggests that people with a higher level of anxiety are more vulnerable to get attached to the excessive use of smartphones. Therefore, people suffering from anxiety makes great use of all these features that a smartphone offers and thus are very prone to develop a problematic use and get addicted to these devices that are a safe haven for them. According to Lee et al. (2014), 83\% of people who own a smartphone use it for messaging purposes, hence, it is safe to assume that anxious individuals will be addicted to it. This leads us to our third hypothesis.

H3: Social Anxiety is positively correlated with smartphone addiction.

\subsubsection{External Locus of Control and Smartphone Addiction}

It is the view of Cloitre et al. (1992) and Stipek (1993) that people who displayed 
signs of inadequate social interactions, achieved a high score on the "powerful others" subscale of locus of control. On the other hand, it was found by Mattick \& Clarke (1998) that there was not a strong relationship between the skills of social interaction of an individual and their locus of control. Moreover, in his study, Koo (2009) found that dependency on online platforms was high in those with higher external locus of control than in internal. This is because people suffering with external locus of control believe that nothing is in their hands and their lives are being controlled by fate, chance, and under the influence other people. They feel like they have no real control over their lives and hence, look toward smartphones and an online presence to control what little they can of their own lives. Therefore, people with internal locus of control have better control over their lives and can regulate their time online, whereas, those with external locus of control are unable to govern their own time online and perceive their smartphones as a sanctuary where they spend as much free time as available, thus forming a dependency on their devices. Leung (2003) also discovered that people who spend most of their time on the internet like the illusion of being in control of their environment. Therefore, in light of this literature, it is safe to assume that people with high levels of external locus of control feel the need to control their environment and their smartphones gives them the perfect ammunition to do that such as controlling their online interactions, controlling their characters in online games, controlling the time they spend on each activity etc. This leads us to our fourth and final hypothesis.

H4: External locus of control is positively correlated with smartphone addiction.

\section{Methodology}

\subsection{Sample Size and Data Collection}

The method used for data collection was questionnaire with closed ended questions. We sent out a total of 250 questionnaires for responses out of which only 240 were useable for our research. We used random sampling in order to recruit candidates for response generation. The participants consisted of students that were studying at undergraduate, graduate and postgraduate level in universities of China. Among the respondents, $56.67 \%$ were males, while $43.33 \%$ were females. Majority of them, i.e. 33.34\%, were between the ages of $21-25$. For this research, $7.5 \%$ of respondents used their smartphones for messaging, $5 \%$ used it for calling, and $12.5 \%$ used it for social networking sites while the majority of them, $75 \%$ used it for all of the above reasons.

\subsection{Questionnaire Design and Measures}

\subsubsection{Loneliness}

The loneliness scale was adopted from Hays \& DiMatteo (1987) and consisted a total of 8 items whose responses were collected on a 4-point Likert scale from 1 $=$ Never to $4=$ Always. Individuals with higher scores on this scale showed signs 
of deterioration in their social interactions and relationships with people.

\subsubsection{Shyness}

The scale for shyness was adopted from Cheek \& Buss (1981) that included a total of 9 items. The responses were collected on a 5-point Likert scale that ranged from $1=$ Strongly Disagree to $5=$ Strongly Agree. Individuals having a higher rating on this scale had an increasing feeling of uneasiness when put in a social environment.

\subsubsection{Social Anxiety}

The scale used for social anxiety was Social Interaction Anxiety Scale (SIAS) by Fergus et al. (2012). It consisted of 6 items that were recorded on a 5-point Likert scale from $1=$ Not at all characteristic of me to $5=$ Extremely characteristic of me. Individuals with a higher score on this scale appeared to be fearful of the judgment of others passed on to them in a social capacity.

\subsubsection{External Locus of Control}

The scale for external locus of control was adapted from Levenson (1974). We used a total of 6 items, with 3 items each for Chance and Powerful Others. The responses were recorded on a 7 -point Likert scale ranging from $1=$ Strongly Disagree to $7=$ Strongly Agree. Individuals with a higher rating on this scale believe that nothing is in their control and everything happens to them either through luck, fate, or through powerful others.

\subsubsection{Smartphone Addiction}

The scale used for smartphone addiction was Smartphone Addiction Scale (SAS) by Kwon et al. (2013). It consisted of 10 items that were measured on a 6-point Likert scale from $1=$ Strongly Disagree to $6=$ Strongly Agree. People scoring high on this scale were severely addicted to their smartphones.

\section{Results and Discussion}

The demographic profile of the respondents and their descriptive analysis is given below in Table 1 .

Validity refers to whether or not a particular test measures what it claims to measure. We performed a factor analysis test to establish the construct validity of our questionnaire as given in Table 2. The estimates of the Kaiser-Meyer-Olkin (KMO) and Bartlett's Test of Sphericity were used to determine if the validity of our construct was achieved. The KMO measures if the responses were adequate or not. Kaiser (1974) suggested a minimum KMO value of 0.5 for a satisfactory factor analysis to be performed. The Bartlett's Test of Sphericity measures the strength of the relationship among the variables. A non-significant $P$-value means that "The correlation matrix is an identity matrix". Results in Table 3 indicate that the minimum KMO value was achieved $(\mathrm{KMO}=0.783)$ and a statistical significance was also achieved for the Bartlett's Test of Sphericity $(P$-value $=$ 
0.00 ) indicating that the correlation matrix is not and identity matrix. This is an indication that all conditions for factor analysis have been achieved. The factor analysis results show that a total of 8 factors were extracted and the variance proportions of each of the factors were satisfactory. The 8 factors extracted explained $68.62 \%$ of the variance (or Variations).

Table 1. Descriptive analysis.

\begin{tabular}{|c|c|c|c|c|}
\hline Attribute & Frequency & Percent & Valid Percent & Cumulative Percent \\
\hline \multicolumn{5}{|l|}{ Gender } \\
\hline Male & 136 & 56.67 & 56.67 & 56.67 \\
\hline Female & 104 & 43.33 & 43.33 & 100.00 \\
\hline Total & 240 & 100.00 & 100.00 & \\
\hline \multicolumn{5}{|l|}{ Age } \\
\hline $16-20$ & 53 & 22.08 & 22.08 & 22.08 \\
\hline $21-25$ & 80 & 33.34 & 33.34 & 55.42 \\
\hline $26-30$ & 45 & 18.75 & 18.75 & 74.17 \\
\hline $31-35$ & 30 & 12.50 & 12.50 & 86.67 \\
\hline $36-40$ & 20 & 8.33 & 8.33 & 95.00 \\
\hline$>40$ & 12 & 5.00 & 5.00 & 100.00 \\
\hline Total & 240 & 100.00 & 100.00 & \\
\hline \multicolumn{5}{|l|}{ Purpose of Mobile use } \\
\hline Messaging & 18 & 7.50 & 7.50 & 7.50 \\
\hline Calling & 12 & 5.00 & 5.00 & 12.50 \\
\hline Social networking sites & 30 & 12.50 & 12.50 & 25.00 \\
\hline All of the above & 180 & 75.00 & 75.00 & 100.00 \\
\hline Total & 240 & 100.00 & 100.00 & \\
\hline
\end{tabular}

Table 2. Validity test.

\begin{tabular}{ccc}
\hline Test & Measure & Estimate \\
\hline $\begin{array}{c}\text { Kaiser-Meyer-Olkin Measure of } \\
\text { Sampling Adequacy }\end{array}$ & & 0.783 \\
& Approx. Chi-square & 2118.891 \\
Bartlett's Test of Sphericity & df & 561 \\
& Sig. & 0.000 \\
\hline
\end{tabular}


Table 3. Correlation matrix, mean, standard deviation and reliability table.

\begin{tabular}{|c|c|c|c|c|c|c|c|}
\hline \multirow{2}{*}{ Variable } & \multicolumn{7}{|c|}{ Correlation Matrix } \\
\hline & Mean & Std. Dev & 1 & 2 & 3 & 4 & 5 \\
\hline Loneliness (LL) & 8.85 & 3.32 & 0.00 & & & & \\
\hline Shyness (S) & 21.03 & 7.64 & $0.623^{* *}$ & 0.00 & & & \\
\hline Social Anxiety (SOA) & 15.56 & 6.33 & $0.529^{\star *}$ & $0.756^{* *}$ & 0.00 & & \\
\hline External Locus of control (ELC) & 15.56 & 8.02 & $0.371^{\star *}$ & $0.427^{\star *}$ & $0.586^{* *}$ & 0.00 & \\
\hline Smartphone Addiction (SA) & 30.71 & 12.16 & $0.823^{* *}$ & $0.575^{* *}$ & $0.476^{* *}$ & $0.260^{* *}$ & 0.00 \\
\hline
\end{tabular}

${ }^{*}$ Correlation is significant at the 0.01 level (2-tailed). $P$-Values in bold diagonals.

Correlation analysis is a statistical technique for examining the relationship that exists between two quantitative or continuous items. Pearson's correlation coefficient statistic $(\rho)$ is a measure of the statistical strength of association between two continuous or quantitative variables (Rodgers \& Nicewander, 1988). Wackerly et al. (2008) assert that the Pearson's correlation coefficient statistic measure uses the method of covariance to measure the association that exists between two continuous or quantitative variables by providing the magnitude and the direction of the relationship. A correlation coefficient of \pm 1 is interpreted as a perfect positive or negative association. The standard criteria for interpreting the correlation coefficients are presented in Table 4 below.

Analysis in Table 4 presents that all variables are significantly correlated with each other at the $95 \%$ confidence interval with $P$-values $<0.05$.

For a questionnaire to be reliable, all items indicated in the questionnaire should be able to consistently measure their respective attribute (Hinton, 2014). Several researchers such as (Adamson \& Prion, 2013; Devon et al., 2007) have reported the dominant use of Cronbach's alpha reliability statistic for measuring internal consistency reliability. Therefore Cronbach's alpha reliability measure was used to estimate the internal consistency of questionnaire used for this study. Bland \& Altman (1997) suggested Cronbach's alpha values of 0.70 and above as acceptable good reliability measures. Results presented in Table 5 show acceptable Cronbach's alpha measures indicating a good consistency of our questionnaire.

\section{Hypothesis Testing}

Results for the hypothesis testing are presented in Table 3 and Table 4.

\section{$\mathrm{H} 1$ : Loneliness is positively correlated with smartphone addiction}

Results in Table 3 indicate a strong positive correlation coefficient $(\rho)$ of 0.823 between loneliness (LL) and Smartphone Addiction (SA). This correlation coefficient was statistically significant at the 0.01 level (2-tailed). Its corresponding $P$-value was 0.00 indicating that the strength of the relationship is significant. 
Table 4. Person's correlation coefficient interpretation.

\begin{tabular}{cc}
\hline Correlation coefficient $(\rho)$ & Interpretation/meaning \\
\hline $0.00-0.10$ & Negligible correlation \\
$0.10-0.39$ & Weak correlation \\
$0.40-0.69$ & Moderate correlation \\
$0.70-0.89$ & Strong correlation \\
$0.90-0.99$ & Very strong correlation \\
\pm 1 & Perfect negative or positive correlation \\
\hline
\end{tabular}

Source: Overholser \& Sowinski (2008); Mukaka (2012).

Table 5. Reliability test results.

\begin{tabular}{ccc}
\hline Variable & No. of Items measured & Cronbach's Alpha \\
\hline Loneliness (LL) & 5 & 0.769 \\
Shyness (S) & 8 & 0.851 \\
Social Anxiety (SOA) & 6 & 0.838 \\
External Locus of control (ELC) & 5 & 0.854 \\
Smartphone Addiction (SA) & 10 & 0.876
\end{tabular}

This result has been corroborated by researchers such as Sar. (2013) is of the view that relying on the use of smartphones for emotional support and getting rid of loneliness can eventually lead to addiction. This result also supports the conclusion of Engelberg \& Sjoberg (2004) who claimed that lonely people are usually attracted to the use of internet. Park (2005) also reported that lonely college students are at a higher risk to be addicted to smartphones. Consequently, we accept our hypothesis that Loneliness is positively correlated to smartphone addiction.

\section{H2: Shyness is positively correlated with smartphone addiction}

Result in Table 3 presents a moderate positive correlation coefficient $(\rho)$ of 0.575 between shyness (S) and Smartphone Addiction (SA). The estimated correlation coefficient is significant at the $95 \%$ confidence interval with a $\mathrm{P}$-value of 0.00 . This means that individuals who are shy are likely to be addicted to the use of smartphones. Research works of Bian \& Leung (2015), Odacı \& Çelik (2013), Han et al. (2017), and Saunders \& Chester (2008) corroborate the results from our analysis. Conclusions of these researchers present the positive correlation that exists between shyness and smartphone addiction. Therefore we accept our hypothesis that Shyness is positively correlated with smartphone addiction.

H3: Social Anxiety is positively correlated with smartphone addiction

The correlation coefficient between Social Anxiety and Smartphone Addiction 
was estimated to be 0.476 indicating a moderate strength of association as presented in Table 3 . The strength of association is positive and statistically significant $(P$-value $<0.05)$. This result indicates that social anxiety is significantly related to smartphone addiction. Based on this analysis, we can conclude that people with a higher level of anxiety are more vulnerable to get attached to the excessive use of smartphones. Hence we support our hypothesis and conclude that Social Anxiety is positively correlated with Smartphone Addiction.

H4: External locus of control is positively correlated with smartphone addiction

Result in Table 3 presents a positive weak correlation coefficient between External locus of control and Smartphone Addiction with an estimated value of 0.260 . Though there exists a weak association between the variable, the strength of the association is estimated to be significant at the $95 \%$ confidence interval. The result also revealed that External Locus of control is significantly related to Smartphone addiction. This significant association between External Locus of control and Smartphone Addiction indicates that people with high levels of external locus of control feel the need to control their environment and their smartphones gives them the perfect opportunity to do that such as controlling their online interactions, controlling their characters in online games, controlling the time they spend on each activity etc. Hence, we support our hypothesis and conclude that external locus of control is positively correlated with smartphone addiction.

\section{Conclusion}

We conducted this study in an attempt to analyze the effects that an individual's loneliness, shyness, social anxiety and external locus of control has on their addiction towards smartphones. This study was conducted with the undergraduate, graduate, and postgraduate students in China to analyze their behavior. All the hypothesis of this study was proved and there were no conflicts of interest found.

In this research, we found a significant and strong positive correlation between loneliness and excessive use of one's smartphone. The more an individual feels at a distance from everyone else around him the more he is likely to turn to his smartphone for company and entertainment. Moreover, this study found that people who experience shyness have a moderate positive correlation with spending a significant amount of time on their phones. In a social setting, instead of talking to other people, they prefer to use their phones in order to curb their shyness. Furthermore, socially anxious people expect others to continuously judge them in a social environment. To take their mind off such a feeling, they seek refuge in their mobile phones, playing games, texting, or spending time on social networking sites. Finally, individuals who believe that they have no control over their lives prefer to control what little they can. This leads them to use their smartphones more than those who think that things happen because 
they are in control. Therefore, they get addicted to their phone usage.

This study can be consulted by different universities in China and their administration in order to learn the behavior of their students. This study provides an insight into a student's life and their addiction. This research can also be used by the international student departments of universities since they might more prone to loneliness and shyness in a new cultural environment. Moreover, it can be used by educational ministries to develop programs, seminars, and activities that help students with their smartphone addiction. Universities can also use this research when admitting students by taking a test that reveals their dependency on smartphones.

Our study is subject a number of limitations. This research was conducted on a cross-sectional basis which could cause hindrance in results. The respondents' pool was limited to students in China and it might not be helpful for students in other countries. Moreover, the study only used quantitative analysis and the sample size of our respondents was fairly constricted. Future researchers should conduct a longitudinal study to assess the behavior of students over time. Moreover, the pool of respondents can be more diverse to accumulate responses from different universities around the world to get a better understanding of the behavior and addiction. Finally, the researchers can incorporate qualitative analysis to get an in-depth understanding of what leads to the students' loneliness, shyness, anxiety, and addiction to their smartphones.

\section{Conflicts of Interest}

The authors declare no conflicts of interest regarding the publication of this paper.

\section{References}

Adamson, K. A., \& Prion, S. (2013). Reliability: Measuring Internal Consistency Using Cronbach's $\alpha$. Clinical Simulation in Nursing, 9, e179-e180. https://doi.org/10.1016/j.ecns.2012.12.001

Alfano, M. S., Joiner, T. E., \& Perry, M. (1994). Attributional Style: A Mediator of the Shyness-Depression Relationship? Journal of Research in Personality, 28, 287-300. https://doi.org/10.1006/jrpe.1994.1021

Asendorpf, J. B. (1991). Development of Inhibited Children's Coping with Unfamiliarity. Child Development, 62, 1460-1474. https://doi.org/10.2307/1130819

Asher, S. R., \& Paquette, J. A. (2003). Loneliness and Peer Relations in Childhood. Current Directions in Psychological Science, 12, 75-78. https://doi.org/10.1111/1467-8721.01233

Bian, M., \& Leung, L. (2015). Linking Loneliness, Shyness, Smartphone Addiction Symptoms, and Patterns of Smartphone Use to Social Capital. Social Science Computer Review, 33, 61-79. https://doi.org/10.1177/0894439314528779

Bland, J. M., \& Altman, D. G. (1997). Statistics Notes: Cronbach’s Alpha. BMJ, 314, 572. https://doi.org/10.1136/bmj.314.7080.572

Brook, J. S., \& Newcomb, M. D. (1995). Childhood Aggression and Unconventionality: 
Impact on Later Academic Achievement, Drug Use, and Workforce Involvement. Journal of Genetic Psychology, 156, 393-410. https://doi.org/10.1080/00221325.1995.9914832

Casey, B. M. (2012). Linking Psychological Attributes to Smart Phone Addiction, Face-toFace Communication, Present Absence and Social Capital. Graduation Project, Hong Kong: Graduate School of the Chinese University of Hong Kong.

Charlton, J. P., \& Danforth, I. D. (2010). Validating the Distinction between Computer Addiction and Engagement: Online Game Playing and Personality. Behavior \& Information Technology, 29, 601-613. https://doi.org/10.1080/01449290903401978

Cheek, J. M., \& Buss, A. H. (1981). Shyness and Sociability. Journal of Personality and Social Psychology, 41, 330-339. https://doi.org/10.1037/0022-3514.41.2.330

Chen, X. (2018). Culture and Shyness in Childhood and Adolescence. New Ideas in Psychology, 53, 58-66. https://doi.org/10.1016/j.newideapsych.2018.04.007

Chotpitayasunondh, V., \& Douglas, K. M. (2016). How "Phubbing" Becomes the Norm: The Antecedents and Consequences of Snubbing via Smartphone. Computers in $\mathrm{Hu}$ man Behavior, 63, 9-18. https://doi.org/10.1016/j.chb.2016.05.018

Cloitre, M., Heimberg, R. G., Liebowitz, M. R., \& Gitow, A. (1992). Perceptions of Control in Panic Disorder and Social Phobia. Cognitive Therapy and Research, 16, 569-577. https://doi.org/10.1007/BF01175142

Coplan, R. J., \& Armer, M. (2007). A "Multitude" of Solitude: A Closer Look at Social Withdrawal and Nonsocial Play in Early Childhood. Child Development Perspectives, 1, 26-32. https://doi.org/10.1111/j.1750-8606.2007.00006.x

Demirci, K., Akgönül, M., \& Akpinar, A. (2015). Relationship of Smartphone Use Severity with Sleep Quality, Depression, and Anxiety in University Students. Journal of Behavioral Addictions, 4, 85-92. https://doi.org/10.1556/2006.4.2015.010

Devon, H. A., Block, M. E., Moyle-Wright, P., Ernst, D. M., Hayden, S. J., Lazzara, D. J., Savoy, S. M., \& Kostas-Polston, E. (2007). A Psychometric Toolbox for Testing Validity and Reliability. Journal of Nursing Scholarship, 39, 155-164. https://doi.org/10.1111/j.1547-5069.2007.00161.x

Dobkin, P., Tremblay, R., Masse, L., \& Vitaro, F. (1995). Individual and Peer Characteristics in Predicting Boys' Early Onset of Substance Abuse: A Seven-Year Longitudinal Study. Child Development, 66, 1198-1214. https://doi.org/10.2307/1131807

Duy, B. (2003). The Effect of Cognitive-Behavioral Approach Group Psychological Counseling on Loneliness and Dysfunctional Attitudes. Unpublished Doctoral Thesis. Ankara: Ankara University.

Elhai, J. D., Dvorak, R. D., Levine, J. C., \& Hall, B. J. (2017). Problematic Smartphone Use: A Conceptual Overview and Systematic Review of Relations with Anxiety and Depression Psychopathology. Journal of Affective Disorders, 207, 251-259. https://doi.org/10.1016/j.jad.2016.08.030

Emineoğlu, M. (2018). The Mediating Role of Psychological Resilience between Social and Emotional Loneliness and Peer Bullying in Adolescents. Published Master Thesis. Bayburt: Bayburt University.

Engelberg, E., \& Sjoberg, L. (2004). Internet Use, Social Skills and Adjustment. Cyber Psychology \& Behavior, 7, 41-47. https://doi.org/10.1089/109493104322820101

Ensminger, M. E., Juon, H. S., \& Fothergill, K. E. (2002). Childhood and Adolescent Antecedents of Substance Use in Adulthood. Addiction, 97, 833-844.

https://doi.org/10.1046/j.1360-0443.2002.00138.x 
Evers, A., Frese, M., \& Cooper, C. L. (2000). Revisions and Further Developments of the Occupational Stress Indicator: LISREL Results from Four Dutch Studies. Journal of Occupational and Organizational Psychology, 73, 221-240. https://doi.org/10.1348/096317900166994

Fergus, T. A., Valentiner, D. P., McGrath, P. B., Gier-Lonsway, S. L., \& Kim, H. S. (2012). Short Forms of the Social Interaction Anxiety Scale and the Social Phobia Scale. Journal of Personality Assessment, 94, 310-320. https://doi.org/10.1080/00223891.2012.660291

Gazelle, H., \& Ladd, G. W. (2003). Anxious Solitude and Peer Exclusion: A Diathesis-Stress Model of Internalizing Trajectories in Childhood. Child Development, 74, 257-278. https://doi.org/10.1111/1467-8624.00534

Gianakos, I. (2002). Predictors of Coping with Work Stress: The Influences of Sex, Gender Role, Social Desirability, and Locus of Control. Sex Roles, 46, 149-158. https://doi.org/10.1023/A:1019675218338

Gore, J. S., Griffin, D. P., and McNierney, D. (2016). Does Internal or External Locus of Control Have a Stronger Link to Mental and Physical Health? Psychological Studies, 61, 181-196. https://doi.org/10.1007/s12646-016-0361-y

Grieve, R., Indian, M., Witteveen, K., Tolan, G. A., \& Marrington, J. (2013). Face-to-Face or Facebook: Can Social Connectedness Be Derived Online? Computers in Human Behavior, 29, 604-609. https://doi.org/10.1016/j.chb.2012.11.017

Han, L., Geng, J., Jou, M., Gao, F., \& Yang, H. (2017). Relationship between Shyness and Mobile Phone Addiction in Chinese Young Adults: Mediating Roles of Self-Control and Attachment Anxiety. Computers in Human Behavior, 76, 363-371. https://doi.org/10.1016/j.chb.2017.07.036

Han, L., Xu, J., Bian, Y., Gao, F., \& Ren, Y. (2016). Effects of Problem Characteristics on the Online Helping Behavior of Shy Individuals. Computers in Human Behavior, 64, 531-536. https://doi.org/10.1016/j.chb.2016.07.056

Hawi, N. S. (2012). Internet Addiction among Adolescents in Lebanon. Computers in Human Behavior, 28, 1044-1053. https://doi.org/10.1016/j.chb.2012.01.007

Hawkins, J. D., Catalano, R. F., \& Miller, J. Y. (1992). Risk and Protective Factors for Alcohol and Other Drug Problems in Adolescence and Early Adulthood: Implications for Substance Abuse Prevention. Psychological Bulletin, 112, 64-105. https://doi.org/10.1037/0033-2909.112.1.64

Hays, R., \& DiMatteo, M. R. (1987). A Short-Form Measure of Loneliness. Journal of Personality Assessment, 51, 69-81. https://doi.org/10.1207/s15327752jpa5101_6

Henderson, L., \& Zimbardo, P. (2001). Shyness as a Clinical Condition: The Stanford Model. In W. R. Crozier, \& L. E. Alden (Eds.), International Handbook of Social Anxiety: Concepts, Research and Interventions Relating to the Self and Shyness (p. 431-447). Hoboken, NJ: John Wiley \& Sons Ltd.

Hinton, P. R. (2014). Statistics Explained. London: Routledge. https://doi.org/10.4324/9781315797564

Hormes, J. M., Kearns, B., \& Timko, C. A. (2014). Craving Facebook? Behavioral Addiction to Online Social Networking and Its Association with Emotion Regulation Deficits. Addiction, 109, 2079-2088. https://doi.org/10.1111/add.12713

Hsiao, C., Lee, Y.-H., \& Chen, H.-H. (2016). The Effects of Internal Locus of Control on Entrepreneurship: The Mediating Mechanisms of Social Capital and Human Capital. The International Journal of Human Resource Management, 27, 1158-1172. https://doi.org/10.1080/09585192.2015.1060511 
Huang, R., Lu, Z., Liu, J., You, Y., Pan, Z., Wei, Z., He, Q., \& Wang, Z. (2009). Features and Predictors of Problematic Internet Use in Chinese College Students. Behaviour \& Information Technology, 28, 485-490. https://doi.org/10.1080/01449290701485801

Jackson, T., Fritch, A., \& Nagasaka, T. (2002). Towards Explaining the Association between Shyness and Loneliness: A Path Analysis with American College Students. Social Behavior Personality, 30, 263-270. https://doi.org/10.2224/sbp.2002.30.3.263

Jatmiko, A. (2016). Sense of Place dan Social Anxiety Bagi Mahasiswa Baru Pendatang. Jurnal Bimbingan dan Konseling, 3, 217-228.

Jones, W. (1982). Loneliness and Social Behavior. In L. A. Peplau, \& D. Perlman (Eds.), Loneliness: A Sourcebook of Current Theory, Research and Therapy (pp. 283-52). New York, NY: Wiley-Interscience.

Kabasakal, Z. (2015). Life Satisfaction and Family Functions As-Predictors of Problematic Internet Use in University Students. Computers in Human Behavior, 53, 294-304. https://doi.org/10.1016/j.chb.2015.07.019

Kaiser, H. F. (1974). An Index of Factorial Simplicity Psychometrics. Psychometrika, 39, 31-36. https://doi.org/10.1007/BF02291575

Kara, N. S., Çetin, M. Ç., Dönmez, A., Kara, M., \& Genç, H. İ. (2020). A Study on the Relationship between the Levels of Loneliness and Smartphone Addiction of Students Who Are Studying at the Faculty of Sports Science. Asian Journal of Education and Training, 6, 213-218. https://doi.org/10.20448/journal.522.2020.62.213.218

Keenan, A., \& McBain, G. D. M. (1979). Effects of Type a Behaviour, Intolerance of Ambiguity, and Locus of Control on the Relationship between Role Stress and Work-Related Outcomes. Journal of Occupational Psychology, 52, 277-285. https://doi.org/10.1111/j.2044-8325.1979.tb00462.x

Kellam, S. G., Simon, M. B., \& Ensminger, M. E. (1983). Antecedents in First Grade of Teenage Substance Use and Psychological Well-Being: A Ten-Year Community-Wide Prospective Study. In D. F. Ricks, \& B. S. Dohrenwend (Eds.), Origins of Psychopathology (pp. 17-42). Cambridge: Cambridge University Press.

Koh, E. Y., \& Kim, E. (2017). The Impacts of Anxiety and Depression on Smartphone Addiction: Focusing on the Moderating Effect of Gender. Journal of Digital Convergence, 15, 419-429. https://doi.org/10.14400/JDC.2017.15.5.419

Koo, D. M. (2009). The Moderating Role of Locus of Control on the Links between Experiential Motives and Intention to Play Online Games. Computers in Human Behavior, 25, 466-474. https://doi.org/10.1016/j.chb.2008.10.010

Kwon, M., Kim, D. J., Cho, H., \& Yang, S. (2013). The Smartphone Addiction Scale: Development and Validation of a Short Version for Adolescents. PLOS ONE, 8, e83558. https://doi.org/10.1371/journal.pone.0083558

Laghi, F., Schneider, B. H., Vitoroulis, I., Coplan, R. J., Baiocco, R., Amichai-Hamburger, Y., Flament, M. et al (2013). Knowing When Not to Use the Internet: Shyness and Adolescents' On-Line and Off-Line Interactions with Friends. Computers in Human Behavior, 29, 51-57. https://doi.org/10.1016/j.chb.2012.07.015

Lazarus, R. S., \& Folkman, S. (1984). Stress, Appraisal, and Coping. New York, NY: Springer Publishing Company.

Leary, M. R. (1983). Social Anxiousness: The Construct and Its Measurement. Journal of Personality Assessment, 47, 66-75. https://doi.org/10.1207/s15327752jpa4701_8

Lee, I. S. (2014). A Study on the Smartphone Addiction, Anxiety, Depression, and Self-Control of Worker. Journal of the Korean Society for Multicultural Health, 4, 19-27. 
Lee, Y., Chang, C., Lin, Y., \& Cheng, Z. H. (2014). The Dark Side of Smartphone Usage: Psychological Traits, Compulsive Behavior and Technostress. Computers in Human Behavior, 31, 373-383. https://doi.org/10.1016/j.chb.2013.10.047

Lepp, A., Li, J., Barkley, J. E., \& Salehi-Esfahani, S. (2015). Exploring the Relationships between College Students' Cell Phone Use, Personality and Leisure. Computers in Human Behavior, 43, 210-219. https://doi.org/10.1016/j.chb.2014.11.006

Leung, L. (2003). Impacts of Net-Generation Attributes, Seductive Properties of the Internet, and Gratifications-Obtained on Internet Use. Telematics \& Informatics, 20, 107-129. https://doi.org/10.1016/S0736-5853(02)00019-9

Levenson, H. (1974). Activism and Powerful Others: Distinctions within the Concept of Internal-External Control. Journal of Personality Assessment, 38, 377-383.

https://doi.org/10.1080/00223891.1974.10119988

Mattick, R. P., \& Clarke, J. C. (1998). Development and Validation of Measures of Social Phobia Scrutiny Fear and Social Interaction Anxiety. Behaviour Research and Therapy, 36, 455-470. https://doi.org/10.1016/S0005-7967(97)10031-6

McKenna, K. Y. A., \& Bargh, J. A. (2000). Plan 9 from Cyberspace: The Implications of the Internet for Personality and Social Psychology. Personality and Social Psychology Review, 4, 57-75. https://doi.org/10.1207/S15327957PSPR0401_6

Mukaka, M. M. (2012). Statistics Corner: A Guide to Appropriate Use of Correlation Coefficient in Medical Research. Malawi Medical Journal, 24, 69-71.

Müller, K. W., Glaesmer, H., Brähler, E., Woelfling, K., \& Beutel, M. E. (2014). Prevalence of Internet Addiction in the General Population: Results from a German Population-Based Survey. Behaviour \& Information Technology, 33, 757-766.

https://doi.org/10.1080/0144929X.2013.810778

Newton, T. J., \& Keenan, A. (1990). The Moderating Effect of the Type a Behavior Pattern and Locus of Control upon the Relationship between Change in Job Demands and Change in Psychological Strain. Human Relations, 43, 1229-1255. https://doi.org/10.1177/001872679004301204

Odacı, H., \& Çelik, Ç. B. (2013). Who Are Problematic Internet Users? An Investigation of the Correlations between Problematic Internet Use and Shyness, Loneliness, Narcissism, Aggression and Self Perception. Computers in Human Behavior, 29, 2382-2387. https://doi.org/10.1016/j.chb.2013.05.026

Oh, W., Rubin, K. H., Bowker, J. C., Booth-LaForce, C., Rose-Krasnor, L., \& Laursen, B. (2008). Trajectories of Social Withdrawal from Middle Childhood to Early Adolescence. Journal of Abnormal Child Psychology, 36, 553-566.

https://doi.org/10.1007/s10802-007-9199-Z

Overholser, B. R., \& Sowinski, K. M. (2008). Biostatistics Preview: Part 2. Nutrition in Clinical Practice, 23, 76-84. https://doi.org/10.1177/011542650802300176

Park, W. K. (2005). Mobile Phone Addiction. In R. Ling, \& P. E. Pedersen (Eds.), Mobile Communications: Re-Negotiation of the Social Sphere (pp. 253-272). London: Springer. https://doi.org/10.1007/1-84628-248-9_17

Peplau, L. A., Russell, D., \& Heim, M. (1979). The Experience of loneliness. In I. Frieze, D. Bar-Tal, \& J. S. Carroll (Eds.), New Approaches to Social Problems: Applications of Attribution Theory (pp. 53-78). San Francisco, CA: Jossey-Bass.

Pilkonis, P. A. (1977). Shyness, Public and Private, and Its Relationship to Other Measures of Social Behavior. Journal of Personality, 45, 585-595. https://doi.org/10.1111/j.1467-6494.1977.tb00173.x

Pugh, S. (2017). Investigating the Relationship between Smartphone Addiction, Social 
Anxiety, Self-Esteem, Age \& Gender. BA Hons in Psychology Thesis, Dublin: Dublin Business School.

Rodgers, J. L., \& Nicewander, W. A. (1988). Thirteen Ways to Look at the Correlation Coefficient. The American Statistician, 42, 59-66. https://doi.org/10.2307/2685263

Romney, D. M., \& Bynner, J. M. (1997). A Re-Examination of the Relationship between Shyness, Attributional Style, and Depression. Journal of Genetic Psychology, 158, 261-270. https://doi.org/10.1080/00221329709596666

Rotter, J. B. (1966). Generalized Expectancies for Internal versus External Control of Reinforcement. Psychological Monographs, 80, 1-28. https://doi.org/10.1037/h0092976

Rubin, K. H., Coplan, R. J., \& Bowker, J. C. (2009). Social Withdrawal in Childhood. Annual Review of Psychology, 60, 141-171.

https://doi.org/10.1146/annurev.psych.60.110707.163642

Sar., A. H. (2013). Examination of Loneliness and Mobile Phone Addiction Problem Observed in Teenagers from the Some Variables. The Journal of Academic Social Science Studies, 6, 1207-1220. https://doi.org/10.9761/jasss_709

Saunders, P. L., \& Chester, A. (2008). Shyness and the Internet: Social Problem or Panacea? Computers in Human Behavior, 24, 2649-2658. https://doi.org/10.1016/j.chb.2008.03.005

Schlenker, B., \& Leary, M. (1982). Social Anxiety and Self-Presentation: A Conceptualization Model. Psychological Bulletin, 92, 641-669.

https://doi.org/10.1037/0033-2909.92.3.641

Shell, M. D., Gazelle, H., \& Faldowski, R. A. (2014). Anxious Solitude and the Middle School Transition: A Diathesis X Stress Model of Peer Exclusion and Victimization Trajectories. Developmental Psychology, 50, 1569-1583. https://doi.org/10.1037/a0035528

Sloan, W. W., \& Solano, C. H. (1984). The Conversational Styles of Lonely Males with Strangers and Roommates. Personality \& Social Psychology Bulletin, 10, 293-301. https://doi.org/10.1177/0146167284102016

Solano, C. H., Batten, P. G., \& Parish, E. A. (1982). Loneliness and Patterns of Self-Disclosure. Journal of Personality \& Social Psychology, 43, 524-531. https://doi.org/10.1037/0022-3514.43.3.524

Spitzberg, B. H., \& Canary, D. J. (1985). Loneliness and Relationally Competent Communication. Journal of Social \& Personal Relationships, 2, 387-402. https://doi.org/10.1177/0265407585024001

Stipek, D. J. (1993). Motivation to Learn: From Theory to Practice. Needham Heights, MA: Allyn \& Bacon.

Suler, J. (2004). The Online Disinhibition Effect. Cyberpsychology \& Behavior, 7, 321-326. https://doi.org/10.1089/1094931041291295

Tan, J. F., Ai, Y. T., Wen, X., Wu, Y., \& Wang, W. N. (2016). Relationship between Shyness and Loneliness among Chinese Adolescents: Social Support as Mediator. Social Behavior and Personality, 44, 201-208. https://doi.org/10.2224/sbp.2016.44.2.201

Thomée, S., Härenstam, A., \& Hagberg, M. (2011). Mobile Phone Use and Stress, Sleep Disturbances, and Symptoms of Depression among Young Adults-A Prospective Cohort Study. BMC Public Health, 11, Article No. 66. https://doi.org/10.1186/1471-2458-11-66

Tian, Y., Bian, Y., Han, P., Gao, F., \& Wang, P. (2017). Associations between Psychosocial Factors and Generalized Pathological Internet use in Chinese University Students: A 
Longitudinal Crosslagged Analysis. Computers in Human Behavior, 72, 178-188. https://doi.org/10.1016/j.chb.2017.02.048

Townsend, A. M. (2000). Life in the Real-Time City: Mobile Telephones and Urban Metabolism. Journal of Urban Technology, 7, 85-104. https://doi.org/10.1080/713684114

Valkenburg, P. M., Peter, J., \& Schouten, A. P. (2006). Friend Networking Sites and Their Relationship to Adolescents' Well-Being and Social Self-Esteem. Cyber Psychology\& Behavior, 9, 584-590. https://doi.org/10.1089/cpb.2006.9.584

Van den Brande, W., Baillien, E., De Witte, H., Vander Elst, T., \& Godderis, L. (2016). The Role of Work Stressors, Coping Strategies and Coping Resources in the Process of Workplace Bullying: A Systematic Review and Development of a Comprehensive Model. Aggression and Violent Behavior, 29, 61-71. https://doi.org/10.1016/j.avb.2016.06.004

Van, A. M., Mancini, C., \& Oakman, J. M. (1998). The Relationship of Behavioral Inhibition and Shyness to Anxiety Disorder. Journal of Nervous \& Mental Disease, 186, 425-431. https://doi.org/10.1097/00005053-199807000-00007

Wackerly, D. D., Mendenhall III, W., \& Scheaffer, R. L. (2008). Multivariate Probability distributions. In D. D. Wackerly, W. Mendenhall, \& R. L. Scheaffer (Eds.), Mathematical Statistics with Applications (7th ed., pp. 223-295). Belmont, CA: Thomson Brooks/Cole.

Weiss, R. S. (1973). Loneliness: The Experience of Emotional and Social Isolation. Cambridge, MA: MIT Press.

Yen, J. Y., Ko, C. H., Yen, C. F., Wu, H. Y., \& Yang, M. J. (2007). The Comorbid Psychiatric Symptoms of Internet Addiction: Attention Deficit and Hyperactivity Disorder (ADHD), Depression, Social Phobia, and Hostility. Journal of Adolescent Health, 41, 93-98. https://doi.org/10.1016/j.jadohealth.2007.02.002

Yıldız, M. A., \& Duy, V. B. (2014). Adaptation of the Short-Form of the UCLA Loneliness Scale (ULS-8) to Turkish for the Adolescents. Düsünen Adam The Journal of Psychiatry and Neurological Sciences, 27, 194-203. https://doi.org/10.5350/DAJPN2014270302

Zhao, J. J., Kong, F., \& Wang, Y. H. (2013). The Role of Social Support and Self-Esteem in the Relationship between Shyness and Loneliness. Personality \& Individual Differences, 54, 577-581. https://doi.org/10.1016/j.paid.2012.11.003 